\title{
Tyrosine Kinase Inhibitor Therapy for Brain Metastases in Non-Small-Cell Lung Cancer: A Primer for Radiologists
}

\author{
(D) C. Dodson, (D)T.J. Richards, (DD.A. Smith, and (D) N.H. Ramaiya
}

\begin{abstract}
SUMMARY: Treatment options for patients who develop brain metastases secondary to non-small-cell lung cancer have rapidly expanded in recent years. As a key adjunct to surgical and radiation therapy options, systemic therapies are now a critical component of the oncologic management of metastatic CNS disease in many patients with non-small-cell lung cancer. The aim of this review article was to provide a guide for radiologists, outlining the role of systemic therapies in metastatic non-small-cell lung cancer, with a focus on tyrosine kinase inhibitors. The critical role of the blood-brain barrier in the development of systemic therapies will be described. The final sections of this review will provide an overview of current imaging-based guidelines for therapy response. The utility of the Response Assessment in Neuro-Oncology criteria will be discussed, with a focus on how to use the response criteria in the assessment of patients treated with systemic and traditional therapies.
\end{abstract}

\footnotetext{
ABBREVIATIONS: $A L K=$ anaplastic lymphoma kinase; CTLA-4 = cytotoxic T-lymphocyte-associated protein 4; EGFR = epidermal growth factor receptor EML4 = echinoderm microtubule-associated protein-like 4; ICI = immune checkpoint inhibitor; NSCLC = non-small-cell lung cancer; PD- $1=$ programmed cell death protein 1; PFS = progression-free survival; PRES = posterior reversible encephalopathy syndrome; QALY = quality-adjusted life years; RANO = Response Assessment in Neuro-Oncology; RECIST = Response Evaluation Criteria in Solid Tumors; ROS1 = C-ras oncogene 1; SRS = stereotactic radiosurgery; TKI = tyrosine kinase inhibitor; WBRT $=$ whole-brain radiation therapy
}

$I^{n}$

recent years, several systemic therapies have been developed that demonstrate efficacy in non-small-cell lung cancer (NSCLC) metastatic to the brain. It is essential for radiologists to be informed about these novel therapeutic agents to evaluate the intracranial response to therapy on imaging in patients undergoing treatment with these drugs. As the systemic chemotherapeutic options for metastatic NSCLC evolve, the assessment of the response of brain metastases on imaging is becoming ever more critical for evaluating and managing patients with metastatic NSCLC.

Brain metastasis is a serious occurrence in patients with cancer and is observed at the highest frequency in NSCLC among all cancer types, with approximately $50 \%$ of patients with NSCLC being affected by brain metastases. ${ }^{1}$ Historically, the prognosis for patients with NSCLC diagnosed with brain metastases has been dismal. Before the advent of FDA-approved targeted therapies, the 5-year survival rate was $2.3 \%$ for patients with NSCLC following a

Received November 10, 2019; accepted after revision January 6, 2020.

From the Department of Radiology (C.D., T.J.R., D.A.S., N.H.R.), University Hospitals Cleveland Medical Center, Case Western Reserve University, Cleveland, Ohio; and Department of Radiology and Imaging Sciences (T.J.R.), University of Utah Hospital, Salt Lake City, Utah.

Please address correspondence to Daniel A. Smith, MD, University Hospitals Cleveland Medical Center, Case Western Reserve University, Department of Radiology, 11100 Euclid Ave, Cleveland, OH 44106; e-mail: Daniel.Smith3@UHhospitals.org

- Indicates open access to non-subscribers at www.ajnr.org

http://dx.doi.org/10.3174/ajnr.A6477 diagnosis of brain metastases. ${ }^{2}$ Cytotoxic chemotherapeutics are largely ineffective intracranially due to their inability to cross the BBB. Therefore, the standard treatment for CNS metastasis has traditionally been local interventions such as an operation, stereotactic radiosurgery (SRS), and whole-brain radiation therapy (WBRT). ${ }^{3}$

However, the recent discovery of targetable driver mutations such as those involving the epidermal growth factor receptor (EGFR), anaplastic lymphoma kinase (ALK), and C-ras oncogene 1 (ROSI) genes in NSCLC has led to the creation of small-molecule tyrosine kinase inhibitors (TKIs) that target these driver mutations. These TKIs can also traverse the blood-brain barrier to access the brain parenchyma, which has led to increased survival rates for patients with NSCLC with brain metastases. Before the development of TKIs, studies reported the mean overall survival of patients with NSCLC brain metastases as 5 months with motexafin gadolinium chemotherapy plus WBRT and 8 months with cisplatin and etoposide chemotherapy. ${ }^{4,5}$ The concept of using tyrosine kinase inhibitors to target driver mutations has also been investigated in brain metastases from cancer types other than NSCLC. For instance, the EGFR inhibitor lapatinib has shown efficacy in combination with capecitabine in patients with brain metastases originating from HER-2-positive breast cancer. ${ }^{6}$ TKI therapy has also been shown to reduce the incidence of brain metastases in patients with metastatic renal cell cancer. ${ }^{7}$ 
In the era of targeted therapy, selection of the most effective course of therapy relies on molecular genetic testing of a biopsy or cytology sample of malignant tissue. For preservation, tissue samples are typically processed in a formalin-fixed, paraffin-embedded block, while cytology samples are prepared in an artificial cell block or a smear. ${ }^{8}$ Joint guidelines from the College of American Pathologists, the International Association for the Study of Lung Cancer, and the Association for Molecular Pathology categorize EGFR, ALK, and ROS1 as the 3 "must-test" genes for which testing must be offered at all laboratories conducting molecular testing on lung cancer. ${ }^{9}$ The guidelines also assert that EGFR, $A L K$, and ROS1 testing should be performed on all patients with advanced-stage lung adenocarcinoma. Reverse transcription polymerase chain reaction or next-generation sequencing can be used to detect mutations in EGFR, $A L K$, and ROS1 genes. ALK or ROS1 rearrangements can also be detected by fluorescence in situ hybridization.

Despite the high cost of new targeted therapies, the molecular genetic testing and the TKI medications themselves have been shown to be a relatively cost-effective means of treatment. Narita et $\mathrm{al}^{10}$ found that EGFR-mutation testing and gefitinib therapy are more cost-effective than standard chemotherapy and no EGFR testing, with the EGFR testing/gefitinib strategy resulting in 0.036 quality-adjusted life years (QALY) per patient and an incremental cost-effectiveness ratio of US $\$ 32,500$ per QALY gained. Holleman et $\mathrm{al}^{11}$ demonstrated that osimertinib is the most effective EGFR-TKI, with a mean of 2.01 QALY gained per patient at a cost of $€ 128,343$ (US $\$ 143,485$ ) per QALY gained. Djalalov et $\mathrm{al}^{12}$ found that genetic testing for the EML4 (echinoderm microtubule-associated protein-like 4)-ALK fusion gene followed by the first-generation $A L K$-inhibitor crizotinib therapy resulted in a gain of 0.011 QALY, with an incremental cost-effectiveness ratio of CaD $\$ 255,970$ (US \$220,641) per QALY gained compared with standard chemotherapy. Compared with the first-generation $A L K$-inhibitor crizotinib, second-generation alectinib has resulted in a gain of 0.87 QALY, with an incremental cost-effectiveness ratio of US $\$ 39,312$ per QALY. ${ }^{13}$ Of note, most studies on the cost-effectiveness of TKIs have been conducted in Canada, Europe, and Asia, indicating the need for additional studies that examine the cost-effectiveness of these drugs within the American health care system.

While a body of research on the development of targeted therapies for NSCLC brain metastases is rapidly accruing in the field of clinical oncology, much less has been written in the radiology literature. This article, therefore, aims to provide radiologists with a foundational overview of the TKIs that cross the BBB in NSCLC brain metastases and to provide a useful guide for radiologically assessing the effects of these novel drugs in the treatment of NSCLC brain metastases.

\section{Pathophysiology of the Blood-Brain Barrier in Brain Metastasis}

To appreciate the imaging features relevant to systemic treatment of brain metastases, an understanding of the pathophysiology of the $\mathrm{BBB}$ is critical. The $\mathrm{BBB}$ is a selectively permeable, nonfenestrated layer of endothelial cells that enclose the cerebral capillaries. This endothelial cell layer is surrounded by a supportive layer of extracellular matrix, pericytes, and astrocytes. ${ }^{14}$ Tight junctions connect the endothelial cells and allow the BBB to regulate the passage of molecules between cerebral capillaries and the brain parenchyma on the basis of the size and charge of these molecules. ${ }^{15}$ The intercellular tight junctions connecting the epithelial cells of the barrier are impermeable to many hydrophilic systemic chemotherapeutic agents, which explains the low intracranial efficacy of these agents. ${ }^{16,17}$ Efflux pumps unique to the $\mathrm{BBB}$ inhibit the entry of certain compounds into the BBB endothelial cells and also transport compounds out of the endothelial cells to return them to blood vessels, thereby preventing these compounds from reaching the brain parenchyma. Larger molecules are more likely than small molecules to be substrates of these efflux transporters. The small size of TKIs relative to cytotoxic chemotherapeutics may therefore provide a possible mechanism behind the greater BBB penetration with TKIs compared with cytotoxic chemotherapeutic agents. ${ }^{18}$ Additionally, the good cellular permeability of TKIs may also explain this efficacy of TKIs in treating intracranial metastases relative to traditional chemotherapeutics.

Metastasis begins when the metastatic tissue detaches from a primary tumor, enters the extracellular matrix, and migrates into a blood vessel. ${ }^{15}$ The circulating tumor cells migrate hematogeneously to the site of metastasis, where they extravasate from the blood vessel into the parenchyma of the target organ. In the case of brain metastasis, this extravasation from cerebral capillaries into the brain parenchyma requires $\mathrm{BBB}$ penetration. Circulating tumor cells traverse the BBB by interacting with the barrier via mechanisms not yet fully elucidated, after which they establish a secondary tumor in the brain parenchyma. ${ }^{14}$ The expression of vascular endothelial growth factors by the metastatic cancer cells allows the metastatic tissue to establish a blood supply. ${ }^{19}$ This vascular endothelial growth factor secretion also initiates signaling cascades that cause the endothelium of the $\mathrm{BBB}$ to become hyperpermeable, thereby transforming the $\mathrm{BBB}$ into a blood-tumor barrier that has increased permeability to some chemotherapeutic agents. ${ }^{19}$

Metastatic proliferation is further enhanced by the immuneprivileged nature of the brain due to the $\mathrm{BBB}$, as well as the lack of access of many chemotherapeutic drugs to the brain parenchyma, both of which allow NSCLC metastases to establish secondary tumors and thrive in the brain parenchyma. The recent development of targeted therapies that penetrate the BBB affords patients with brain metastases an increased survival that has not previously been achievable with systemic chemotherapeutics (Fig 1).

\section{EGFR-Tyrosine Kinase Inhibitors}

EGFR is a transmembrane glycoprotein and a member of the ErbB receptor tyrosine kinase family. When EGFR is bound to the extracellular ligand, its intracellular domain activates several intracellular pathways implicated in cell proliferation, growth, and survival. Activating mutations in EGFR result in the constitutive activation of downstream signaling cascades that lead to uncontrolled cell proliferation in NSCLC. 


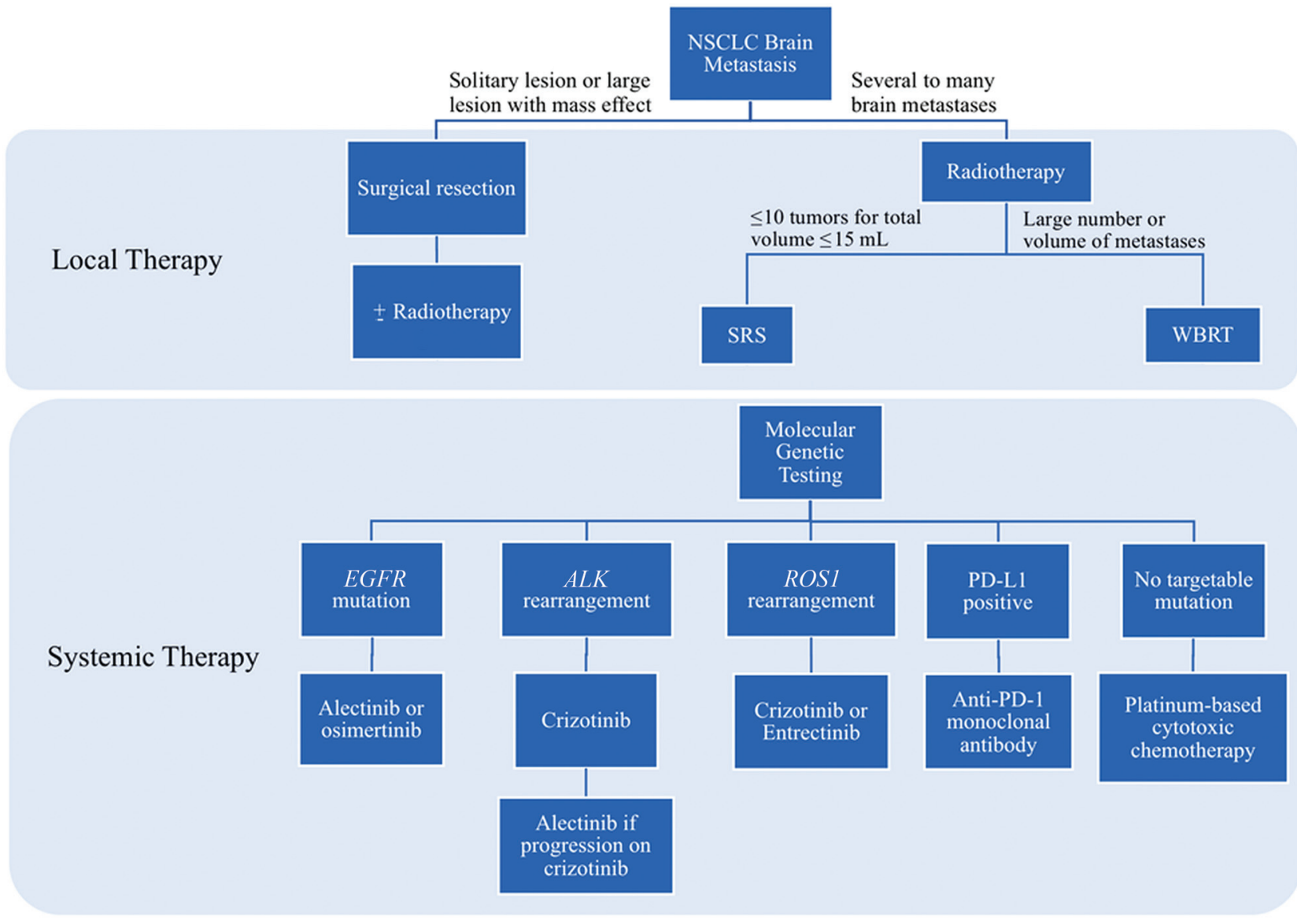

FIG 1. Decision tree for the selection of local and systemic therapies for the treatment of NSCLC brain metastases. PD-L1 indicates programmed death-ligand 1.

Tyrosine kinase inhibitors inhibit EGFR by competitively binding to the adenosine triphosphate binding site on the intracellular tyrosine kinase domain of the receptor. This prevents the tyrosine kinase domain from activating intracellular signaling cascades that would otherwise amplify cell proliferation and survival. A positive EGFR-mutation status has been associated with a higher incidence of brain metastases in patients with advanced nonsquamous NSCLC, so EGFR mutations are especially relevant to the treatment of patients with NSCLC brain metastasis. ${ }^{20}$ The most common EGFR mutations observed in patients with NSCLC are in-frame LREA exon 19 deletions and exon 21 L858R point mutations. ${ }^{21}$

Three generations of TKIs have been developed to treat EGFRmutant NSCLC. The first-generation EGFR-TKIs are erlotinib and gefitinib, both of which inhibit EGFR by binding reversibly to the kinase domain of the receptor. ${ }^{22}$ In a Phase II study investigating gefitinib and erlotinib as first-line treatments for patients diagnosed with EGFR-mutant NSCLC, a high response rate of $83 \%$ was observed in patients with brain metastases treated with either drug, with a median progression-free survival (PFS) of 6.6 months and an overall survival of 15.9 months. ${ }^{23}$ Erlotinib has been observed to have a $\mathrm{BBB}$ permeation rate of $4.4 \%$ in patients following 4 weeks of treatment, with the level of response being proportional to the concentration of the drug in the CSF. In a Phase III study of gefitinib versus carboplatin-paclitaxel in patients with advanced, EGFR-mutated NSCLC and no history of chemotherapy, the gefitinib group had a PFS of 10.8 months, compared with 5.4 months in the traditional chemotherapy group. ${ }^{24}$ The gefitinib group also had a higher response rate of $73.7 \%$ compared with $30.7 \%$ in the carboplatin-paclitaxel group.

Despite the frequently promising initial response observed in first-generation TKIs, CNS tumor recurrence is common, and patients with EGFR-mutated NSCLC typically develop resistance to erlotinib and gefitinib after a median time of 8-10 months on therapy. ${ }^{25}$ These issues led to the creation of second-generation EGFR-TKIs such as afatinib which, unlike its predecessors, binds irreversibly to the EGFR. In a compassionate use program involving patients with NSCLC brain metastases who had failed on platinum-based chemotherapy and had progressed on a first-generation TKI, afatinib produced an overall cerebral response rate of $35 \%$, making afatinib a potentially viable option for patients with NSCLC with bran metastases who have progressed on other chemotherapeutic regimens. ${ }^{26}$

The secondary T790M mutation in the adenosine triphosphate binding site of EGFR is the most common mutation conferring acquired resistance to both first- and second-generation TKIs. ${ }^{27}$ This mutation is, therefore, partially responsible for the resistance to first- or second-generation EGFR-TKIs typically developing after $9-12$ months of therapy. ${ }^{28}$ Osimertinib is an approved third-generation EGFR-TKI that can overcome the 


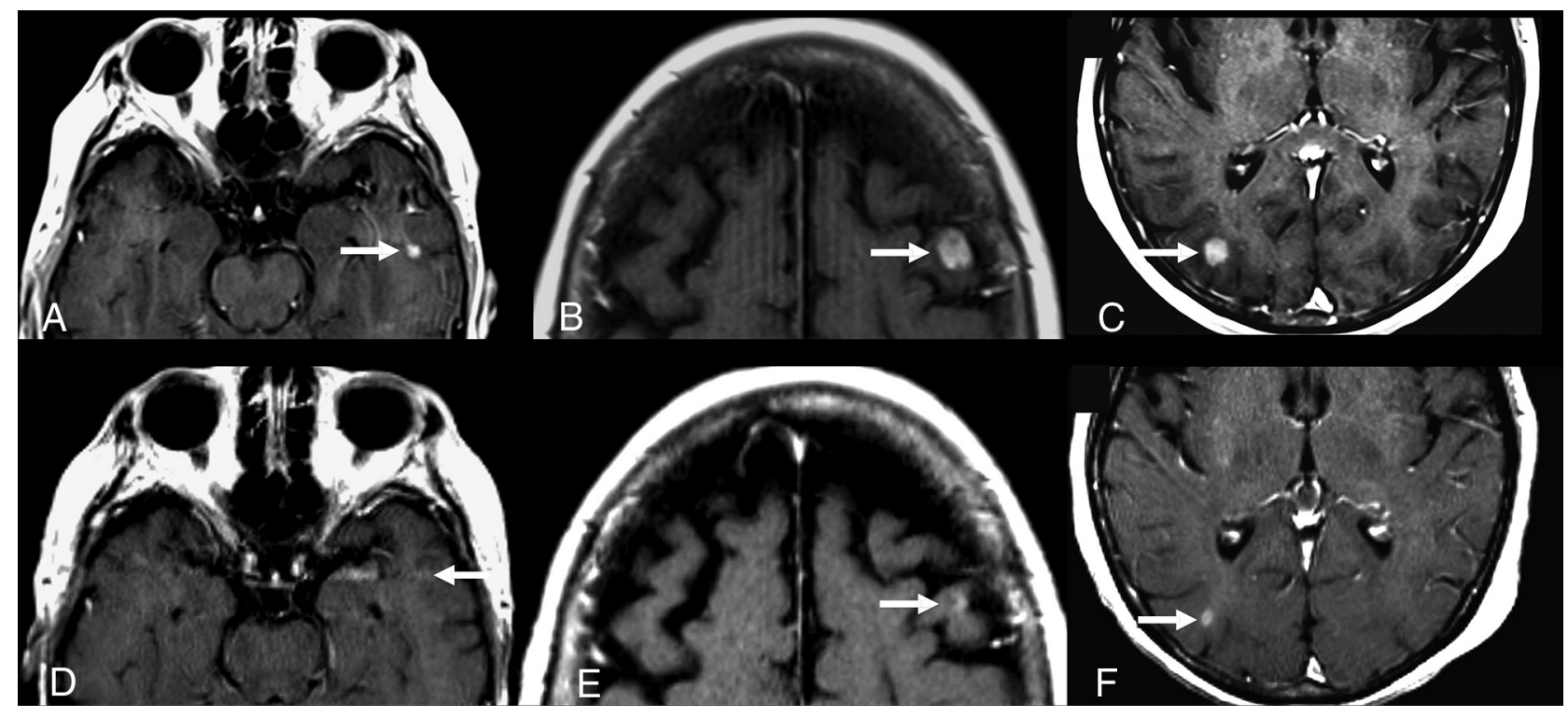

FIG 2. A 73-year-old woman with EGFR-mutated NSCLC, which was initially treated with erlotinib for 9 months with an initial partial response of the primary lung tumor. The patient's primary lung tumor then progressed, and the patient developed brain metastases. Repeat genetic analysis showed that the patient's tumor now had a T790M mutation, so she was started on osimertinib. Images captured before ( $A-C$ ) and 6 weeks after starting treatment with osimertinib $(D-F)$ demonstrate a partial response to therapy of the left temporal $(A$ and $D)$, left frontal $(B$ and $E)$, and right occipital ( $C$ and $F$ ) enhancing brain metastases (arrows).

T790M mutation in patients who have acquired resistance to first- or second-generation EGFR inhibitors (Fig 2). Osimertinib irreversibly binds to EGFR and targets both the initial activating EGFR mutation as well as the T790M mutation, while sparing wild-type EGFR. ${ }^{29}$ Osimertinib and other experimental thirdgeneration TKIs, unlike their first- and second-generation predecessors, are also mutant-selective in that they exert more potent EGFR inhibition on EGFR-mutant cells as opposed to EGFR wild type cells. ${ }^{30}$ In the Phase III AZD9291 Versus Gefitinib or Erlotinib in Patients with Locally Advanced or Metastatic Non-small Cell Lung Cancer (FLAURA) study, patients with EGFR-mutant, advanced NSCLC were assigned to receive either osimertinib or standard EGFR-TKI treatment, which consisted of either erlotinib or gefitinib. A subanalysis of the patients in the FLAURA study with asymptomatic or stable CNS metastases found a $91 \%$ CNS objective response rate in the osimertinib arm compared with $68 \%$ for the standard EGFRTKI arm. ${ }^{31}$ The median PFS was longer with osimertinib versus standard EGFR-TKI therapy (18.9 versus 10.2 months, respectively). ${ }^{32}$ Due to its superior BBB permeability and intracranial efficacy compared with older TKIs, osimertinib is projected to become the new first-line standard of care in the treatment of NSCLC brain metastases. ${ }^{30}$

\section{ALK-Tyrosine Kinase Inhibitors}

Oncogenic rearrangements involving the $A L K$ gene are the second most common mutation in NSCLC and account for approximately $3 \%$ of lung adenocarcinoma cases. ${ }^{21}$ The $A L K$ gene codes for a transmembrane receptor tyrosine kinase that activates intracellular signaling cascades to promote cell proliferation. The oncogenic mutation of $A L K$ consists of the fusion of 2 genes, most frequently $A L K$ and $E M L 4$, to create a fusion of the $A L K$ receptor with mutations in the extracellular domain that allow it to be activated in the absence of ligand binding. Like EGFR inhibitors, $A L K$-TKIs inhibit the $A L K$ receptor by binding to the intracellular tyrosine kinase domain to prevent downstream signal transduction. Up to $70 \%$ of patients with $A L K$ rearrangement with NSCLC develop brain metastases, making $A L K$ gene rearrangements a prime target for TKIs that can penetrate the blood-brain barrier. ${ }^{21}$

The first TKI developed to target $A L K$-rearranged NSCLC was crizotinib. In a retrospective analysis of the patients with $A L K$-rearranged asymptomatic brain metastases included in the PROFILE 1005 and 1007 clinical trials of crizotinib, crizotinib treatment yielded an intracranial disease control rate of 56\% in previously untreated patients with asymptomatic brain metastasis and $62 \%$ in previously treated patients. ${ }^{33}$ The median intracranial time-to-progression was 7 months for the previously untreated group and 13.2 months for the previously treated group. However, eventual progression of pre-existing intracranial lesions or the development of new intracranial lesions during crizotinib therapy was common; this finding aligns with the observation that resistance is typically acquired within 1214 months of the initiation of crizotinib therapy. ${ }^{34}$

Alectinib is a second-generation $A L K$-rearranged TKI that is highly selective for $A L K$ and also blocks the L1196M mutation that confers resistance to crizotinib, therefore providing a treatment option to patients whose intracranial disease has progressed on crizotinib (Fig 3). ${ }^{21}$ In an analysis of the 122 patients with NSCLC brain metastasis included in the Phase III ALEX study, alectinib had a higher overall CNS response rate than crizotinib ( $85.7 \%$ versus $71.4 \%$, respectively) and significantly delayed CNS progression compared with crizotinib in patients with advanced ALK-rearranged NSCLC. ${ }^{35}$ Another Phase III trial, while showing the superiority of alectinib over crizotinib in terms of increased PFS and a lower incidence of CNS progression, also found that 


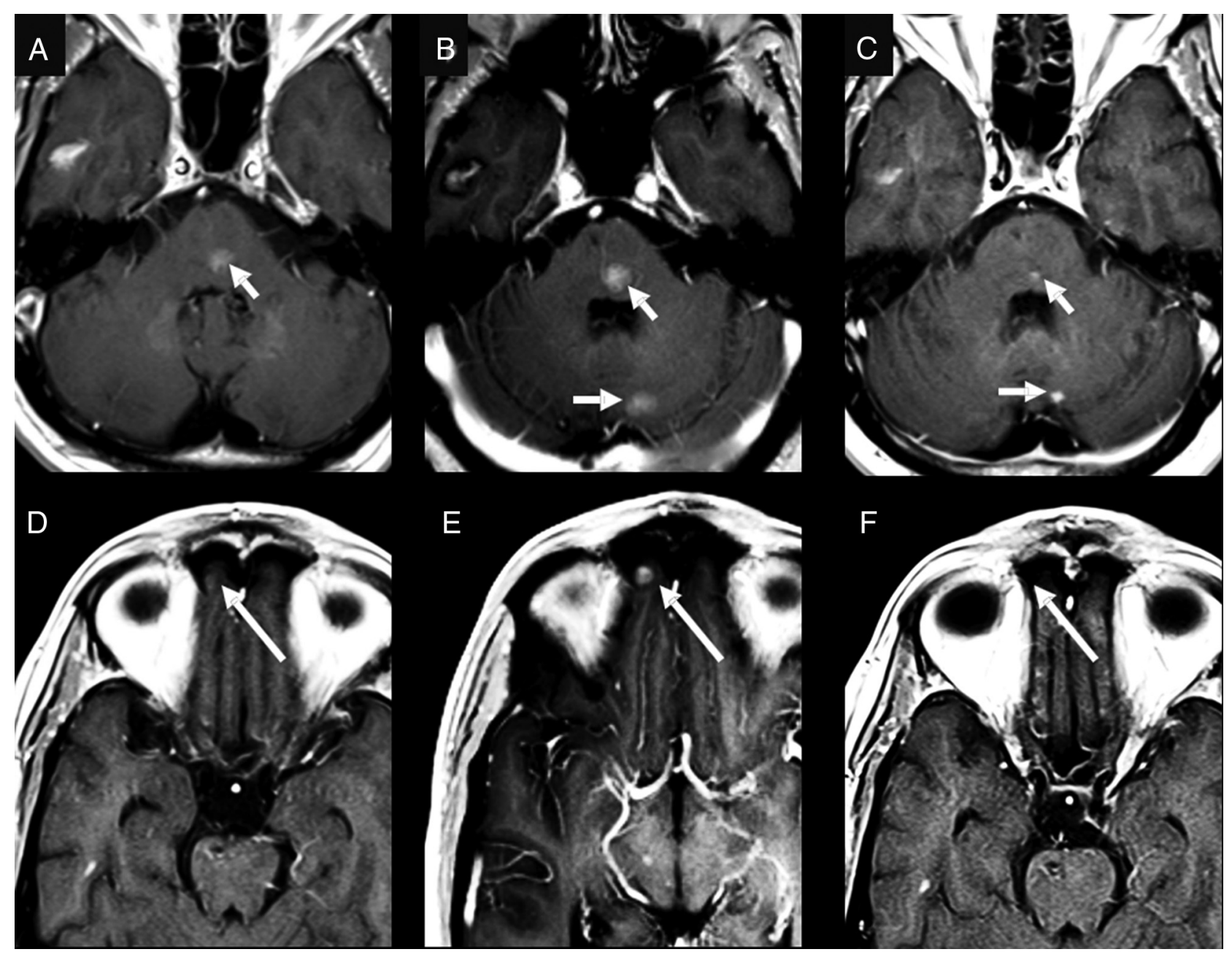

FIG 3. A 58-year-old man who was originally diagnosed with EGFR wild-type and was negative for EML4/ALK adenocarcinoma of the lung. After 3 years of traditional chemotherapy, the patient developed brain metastases. At that time, a biopsy of the patient's pericardial metastasis came back positive for EML4/ALK fusion. Note small metastatic lesions (arrows) at the time of diagnosis of the brain metastases in the pons (A) and medial right orbital gyrus $(D)$. After starting crizotinib, several of the patient's brain metastases, including the lesions in the pons $(B)$ and right medial orbital gyrus $(E)$, increased in size (arrows), and there was development of new lesions such as the lesion in the left cerebellar hemisphere on $B$ (arrow). The patient was then switched to alectinib, which resulted in a partial response in the brain with decreased size of previously identified lesions (arrows) ( $C$ and $F$ ).

alectinib has a superior toxicity profile compared with crizotinib. ${ }^{36}$ The $A L K$-TKIs ceritinib, brigatinib, and lorlatinib have also shown efficacy in NSCLC brain metastases. ${ }^{10,22-24,37-39}$

\section{ROS1 Tyrosine Kinase Inhibitors}

ROS1 is present in $1 \%-2 \%$ of cases of NSCLC and represents another targetable driver mutation in NSCLC brain metastases. ROS1 is a tyrosine kinase that can fuse with several different genes to create multiple ROS1-fusion receptors that lead to overactivation of downstream pathways within the cell that lead to uncontrolled proliferation. Like EGFR and ALK, ROS1 can be inhibited by TKIs that bind to the tyrosine kinase portion within the intracellular domain of the ROS1 receptor. Owing to the sequence homology shared by the ALK and ROS1 proteins, several ALK inhibitors have demonstrated efficacy in ROS1-rearranged NSCLC as well. ${ }^{40}$ For instance, crizotinib has demonstrated intracranial efficacy in ROS1-rearranged NSCLC (Fig 4). A Phase II trial of crizotinib in advanced ROS1+ NSCLC reported an overall response rate of $73.9 \%$ and a PFS of 10.2 months in the 23 patients with measurable CNS lesions at baseline. ${ }^{41}$ The ALK/ROS1/pan-TRK (pan-tropomyosin receptor kinase) inhibitor entrectinib was also studied in patients with ROS1-inhibitor-naive NSCLC, and the authors reported an objective response in 7 of 11 patients with CNS metastases, as well as a CNS response rate of $71 \%$ based on 7 patients with evaluable lesions. ${ }^{42}$

A Phase II study of the ALK inhibitor lorlatinib has also reported an intracranial overall response rate of $56.0 \%$ in 25 patients with brain metastases, including a mixture of patients whose lesions were crizotinib-naïve and crizotinib-refractory. ${ }^{43}$ The ALK inhibitor ceritinib was also examined in ROS1-rearranged NSCLC in a small Phase II study, which reported intracranial disease control in 5 of the 8 patients with CNS metastases enrolled in the study. ${ }^{4}$

\section{TKI Toxicities and Risks}

Overall, EGFR-TKIs are well-tolerated, with fewer than $10 \%$ of patients discontinuing therapy due to adverse events. ${ }^{45}$ Toxic 


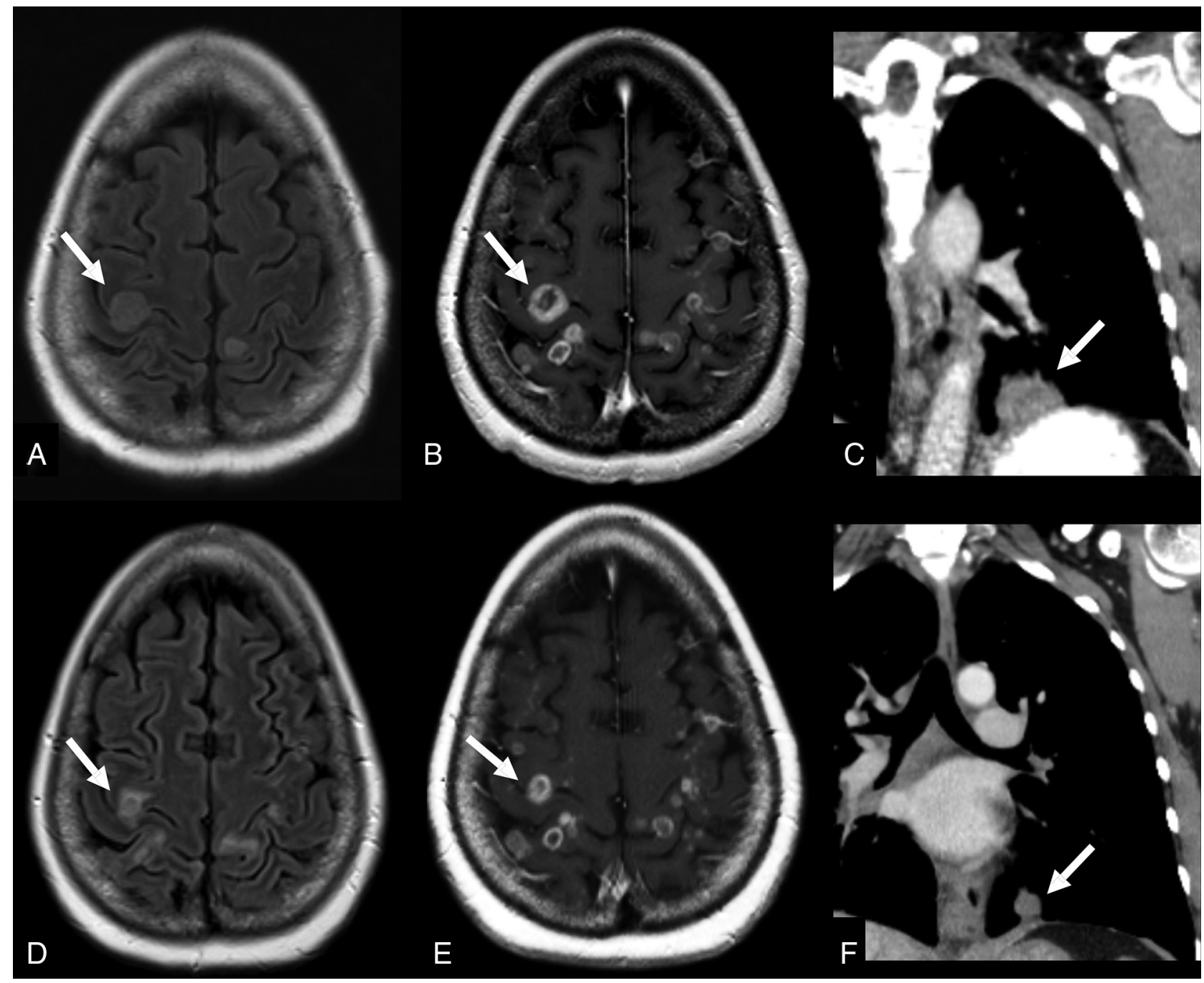

FIG 4. A 50-year-old woman with NSCLC with ROSI-CD74 (Cluster of Differentiation 74) fusion. The patient was initially started on crizotinib. The primary lung tumor was responsive to therapy, but there was progressive disease in the brain. Given the numerous brain metastases, the patient elected to undergo local therapy with whole-brain radiation. The pretherapy images $(A$ and $B)$ demonstrate multiple peripherally enhancing lesions with surrounding hyperintense FLAIR signal consistent with surrounding vasogenic edema (arrows in $A$ and $B$ ). The posttherapy images $(D$ and $E$ ) demonstrate a decrease in the size and surrounding edema of the brain metastases (arrows in $D$ and $E$ ). The patient was also able to remain on crizotinib for systemic therapy, given the favorable response in the chest (arrows in $C$ and $F$ ).

deaths with these 3 EGFR-TKIs are rare, with pneumonitis being the most frequent cause in these agents. ALK inhibitors have been associated with lung toxicity, with the most frequent serious adverse event on $A L K$-inhibitor therapy being pneumonia. ${ }^{46}$ Crizotinib has also been associated with cardiotoxicities such as bradycardia, complete heart block, QT prolongation, and pericarditis. $^{47}$

No major CNS toxicities have been described for EGFR-, $A L K$-, or ROS1-TKIs to date. However, radiation necrosis and pseudoprogression have been described in some TKIs following SRS. Pseudoprogression refers to a short-lived increase in lesion size following therapy commonly due the inflammatory reaction associated with radiation necrosis. Radiation necrosis presenting as pseudoprogression has been reported with alectinib following SRS, as well as with ceritinib following WBRT. ${ }^{48,49}$ A risk with pseudoprogression is mistakenly identifying it as true progression, which could result in unnecessary radiation or surgical CNS interventions. A high index of suspicion is therefore necessary in identifying radiation necrosis and pseudoprogression in patents with NSCLC brain metastases who have undergone radiation therapy followed by a TKI.

Posterior reversible encephalopathy syndrome (PRES) is a reversible neurologic syndrome that manifests as T2-hyperintense vasogenic edema on MR imaging and presents clinically with acute hypertension, seizures, vision abnormalities, and altered mental status. ${ }^{50}$ PRES is most frequently associated with antiangiogenic TKIs that inhibit the vascular endothelial growth factor because PRES is thought to be related to altered cerebral blood flow regulation. However, cases of PRES have been reported with the EGFR inhibitors erlotinib, gefitinib, and osimertinib, as well as the $A L K$ inhibitor crizotinib. ${ }^{50}$ Classically, PRES involves the posterior parietal and occipital lobes but can vary in its distribution, with the most common presentation patterns being a dominant parietal-occipital pattern, superior frontal sulcus pattern, or 
a linear holohemispheric watershed pattern. ${ }^{51}$ As the name suggests, PRES is most often reversible on discontinuation of the offending agent but may progress to hemorrhage or infarction if not promptly treated.

Despite the rare occurrence of radiation necrosis/pseudoprogression or PRES with TKI therapy, the overall risk associated with TKIs remains low. Not only are targeted therapies extending the lives of patients, but they are also doing so with less drug-associated morbidity. Therefore, the minimal toxicities associated with TKIs explain why these medications constitute a powerful breakthrough in the field of thoracic oncology.

\section{Definitive Treatments for Brain Metastases}

SRS was originally approved for treatment of up to 3 brain metastases but is demonstrating success in up to 10 lesions at some institutions. ${ }^{52-54}$ WBRT is typically used in patients with more numerous brain metastases. However, the neurodegenerative effects of WBRT can cause substantial morbidity and impair quality of life while having only a moderately beneficial effect on overall survival. ${ }^{55}$ To minimize neurocognitive damage from WBRT, novel radiation techniques are currently being explored. Hippocampal-sparing WBRT reduces the radiation exposure of the hippocampus while preserving the therapeutic benefit on the grounds that the hippocampus has a low frequency of brain metastasis occurrences, while WBRT-induced hippocampal damage is frequently associated with neurotoxicity. ${ }^{56}$ The neurodegenerative effects of WBRT have also incited effort to reduce the exposure of the brain to radiation via the expansion of SRS to patients with greater numbers of brain metastases in place of WBRT. $^{56}$

Responses of NSCLC brain metastases to radiation therapy have been shown to improve when radiation therapy is combined with immune checkpoint inhibitors (ICIs). The primary ICIs investigated in NSCLC are the anti-programmed cell death protein 1 (anti-PD-1) monoclonal antibodies nivolumab and pembrolizumab, and the anti-cytotoxic T-lymphocyte-associated protein 4 (CTLA-4) monoclonal antibody ipilimumab. These ICIs block tumor cell binding to PD-1, programmed death-ligand 1, or CTLA-4 on immune cells, respectively, to prevent tumor cells from interacting with immune cells and evading the host immune response. The anti-programmed death ligand 1 monoclonal antibody atezolizumab has also been studied in NSCLC. Atezolizumab functions by binding to the programmed deathligand 1 on tumor cells rather than immune cells, which, nevertheless, prevents tumor cells from interacting with immune cells and relieves immune cell suppression as is also seen with the anti-PD-1 and anti-CTLA-4 checkpoint inhibitors.

In a cohort study comparing 34 patients with ICI-naive NSCLC brain metastasis receiving SRS alone with 17 patients receiving SRS concurrently with either nivolumab, pembrolizumab, or atezolizumab, the concurrent SRS/ICI cohort achieved a higher rate of CNS complete response (50\% versus $15.6 \%$ ) and a shorter median time to regression of brain metastases ( 2.5 versus 3.1 months). ${ }^{57}$ A larger retrospective study analyzed the responses to SRS combined with ipilimumab, nivolumab, or pembrolizumab in 260 patients with NSCLC $(n=157)$, melanoma $(n=70)$, or renal cell carcinoma $(n=33)$ with brain metastases. This study found that concurrent SRS/ICI use was associated with a longer overall survival (24.7 months) compared with both SRS alone and SRS with nonconcurrent ICI (12.9 and 14.5 months, respectively). ${ }^{58}$ One explanation for this synergy between ICI and SRS is that SRS facilitates increased release of proinflammatory signals, which augment the efficacy of ICI therapy. Notably, there was no increased risk of neurotoxicity with concurrent SRS/ICI therapy compared with SRS alone in either study.

Imaging Features of EGFR-, ALK-, and ROS1-Mutated NSCLC Brain Metastases. Brain metastases from NSCLC with EGFR, $A L K$, or ROS1 mutations most often appear similar to brain metastases from other common primary malignancies. They typically appear round with well-demarcated borders, exhibit a homogeneous or mostly solid pattern of enhancement, and have surrounding vasogenic edema with mass effect. Several recent case reports and case series have noted development of unique, nearly entirely cystic brain metastases in NSCLC treated with TKIs. ${ }^{59-61}$ In one case series including patients with $A L K$-mutated NSCLC, patients undergoing treatment with crizotinib developed brain metastases characterized by a thin rim of malignant cells with a large mucinous center. ${ }^{59}$ These lesions exhibited no-tominimal peripheral enhancement, no surrounding vasogenic edema, and variable central FLAIR signal, likely related to the amount of proteinaceous content within the central mucinous portion of the lesion. ${ }^{59}$ In all 3 cases, the patient was asymptomatic despite the relatively large size of the lesions. ${ }^{59}$ Another case report described a patient with NSCLC with an unknown genetic mutation status who was treated with erlotinib and developed entirely cystic brain metastases in the subarachnoid space without any associated enhancement. ${ }^{60}$ This patient's lesions responded very well to WBRT, whereas the other cases of cystic metastases after treatment with TKIs did not change significantly after radiation therapy. Another patient with EGFR-mutated NSCLC with a cystic brain metastasis after gefitinib progressed to death from mass effect and subsequent brain herniation. ${ }^{61}$

\section{Guidelines for Response to Therapy}

Due to the poor response of brain metastases to traditional systemic chemotherapy drugs and short life expectancies of these patients in the past, patients with brain metastases were usually excluded from clinical trials. On the rare occasion that these patients were included, they were almost always required to demonstrate stable or treated CNS disease to be eligible for a trial. At least in part due to this limitation, there were no consensus guidelines for monitoring the response of brain metastases to systemic therapy. Trials often extended the Response Evaluation Criteria in Solid Tumors (RECIST) ${ }^{62}$ to evaluate the CNS metastases. Brain metastases were combined with all non-CNS diseases in all other organs as a single compartment for assessment of response. Furthermore, CNS metastases were rarely chosen as target lesions for the assessment of response to therapy. Grouping both CNS and non-CNS metastases as a single compartment is problematic. Traditional systemic chemotherapeutic agents have minimal penetration across the $\mathrm{BBB}$; therefore, CNS lesions may progress while the non-CNS lesions are responding well to therapy. This outcome could force a patient 


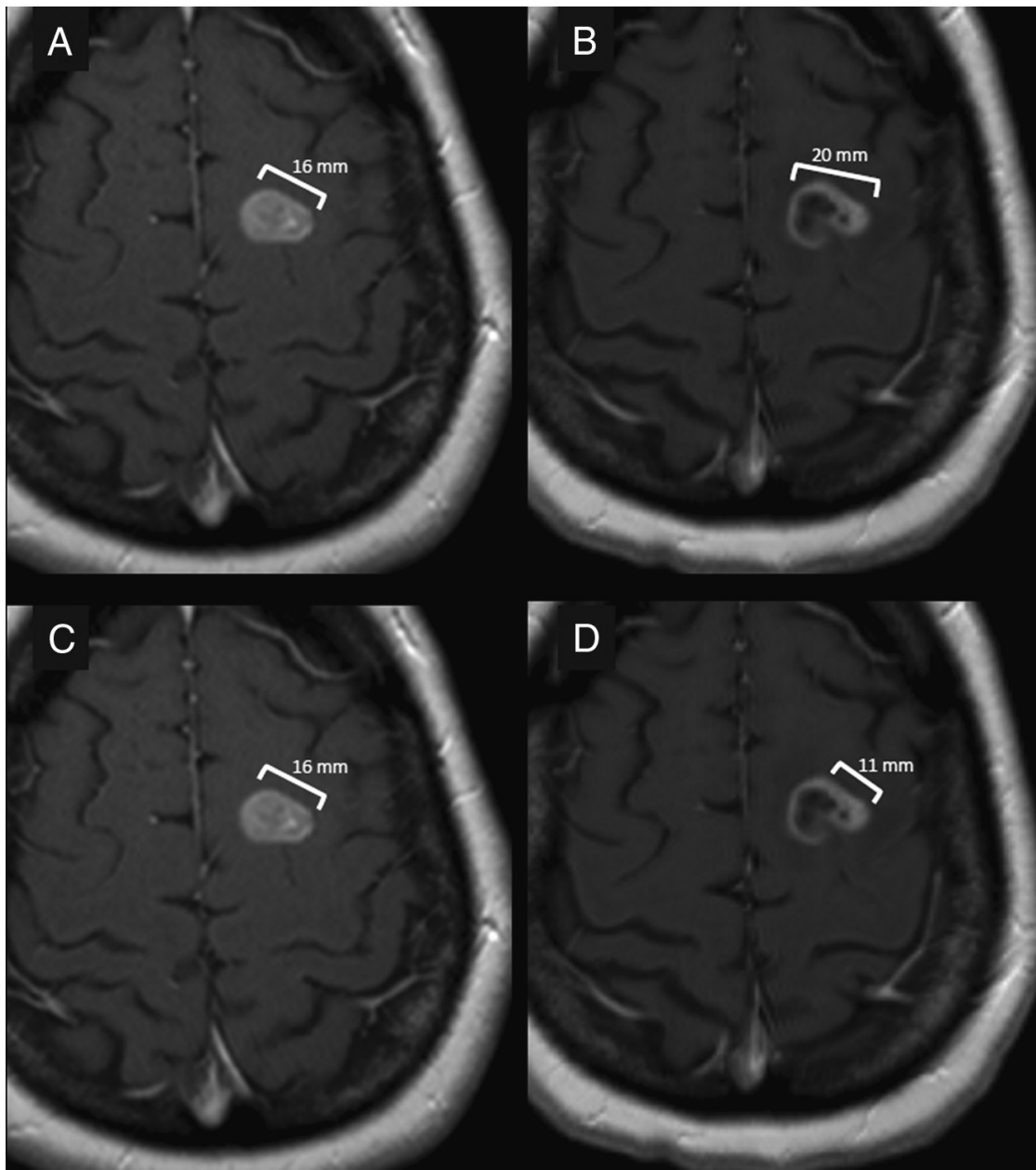

FIG 5. A 58-year-old man with EGFR-mutant NSCLC treated with erlotinib. Pretreatment images $(A$ and $C$ ) show a solidly enhancing left frontal brain metastasis measuring $17 \mathrm{~mm}$ in diameter. Posttreatment images $(B$ and $D)$ demonstrate the implications of different measurement methods on the response to therapy. The measurement on $B$ includes both the cystic and solid components of the lesion and demonstrates an increase of $25 \%$ of the lesion size, consistent with progressive disease. The measurement on $D$ was performed according to the RANO criteria specifications, which only include the enhancing nodular component of the lesion, which has a perpendicular diameter of at least $5 \mathrm{~mm}$. This method of measurement calculated a decrease of $31 \%$, which is consistent with partial response to therapy. This patient continued to have a response to therapy and further decrease in the size of this lesion.

to be removed from the clinical trial even in the setting of a strong response to therapy outside the CNS. If the CNS disease and non-CNS disease are treated as separate compartments, locally progressive CNS disease can be treated with local therapy (eg, SRS, WBRT, and so forth), and the patient can remain on systemic therapy if effective in the non-CNS compartment.

Now that TKIs have shown much greater success in treating NSCLC brain metastases, there is a need for consensus guidelines to assess this response. The Response Assessment in Neuro-Oncology (RANO) group set out to address this problem and to create guidelines for monitoring the CNS response, including guidelines for both brain metastases and leptomeningeal disease. ${ }^{63,64}$ While other criteria such as RECIST and RECIST 1.1 are sometimes used in clinical trials that include patients with brain metastases, the RANO group is the only group to establish criteria pertaining specifically to brain metastases. The remainder of this article will serve as a guide for radiologists to appropriately assess the response to TKIs and other concurrent therapies of brain metastases according to the guidelines established by the RANO group. ${ }^{63}$

\section{Obtaining Adequate Imaging}

The first role of the radiologist in the assessment of brain metastases is to ensure that imaging is obtained with adequate parameters to enable accurate assessment of the response to therapy. MR imaging without and with gadolinium contrast is the ideal imaging technique for assessment of the response to therapy in brain metastases. According to the RANO group, CT with contrast may be used as a substitute in patients with contraindications to MR imaging and/or gadolinium or in areas with limited access to MR imaging; however, MR imaging should be performed whenever possible. ${ }^{63}$ Initial baseline imaging for comparison with further studies should be performed within 4 weeks of the start of treatment. ${ }^{63}$ For contrastenhanced sequences, the MR imaging study should include a postgadolinium T1-weighted sequence with a maximum section thickness of $5 \mathrm{~mm}$ and no gap between slices. Ideally, especially in patients with smaller brain metastases or in trials that allow target lesions $<1 \mathrm{~cm}$ in maximal diameter, a section thickness of $\leq 1.5 \mathrm{~mm}$ should be obtained when feasible. The additional MR imaging sequences in the recommended protocol suggested by the RANO group can be found in their article. ${ }^{63}$

\section{Identifying and Measuring Target Lesions}

For a lesion to be eligible as a target lesion, it must fit the RANO definition of a measurable lesion. A measurable lesion, as defined by the RANO criteria, is one with an enhancing component that is at least $10 \mathrm{~mm}$ in the longest diameter and $5 \mathrm{~mm}$ in the perpendicular, shortaxis diameter that is visible on at least 2 consecutive slices and can be reproducibly measured. ${ }^{63}$ Of note, if the lesion is cystic or mixed cystic and solid, the cystic component should not be included in the measurement (Fig 5). Other features, including cystic-only lesions, leptomeningeal disease, dural-based disease, or lesions with ill-defined borders, are considered nonmeasurable disease (Fig 6). 


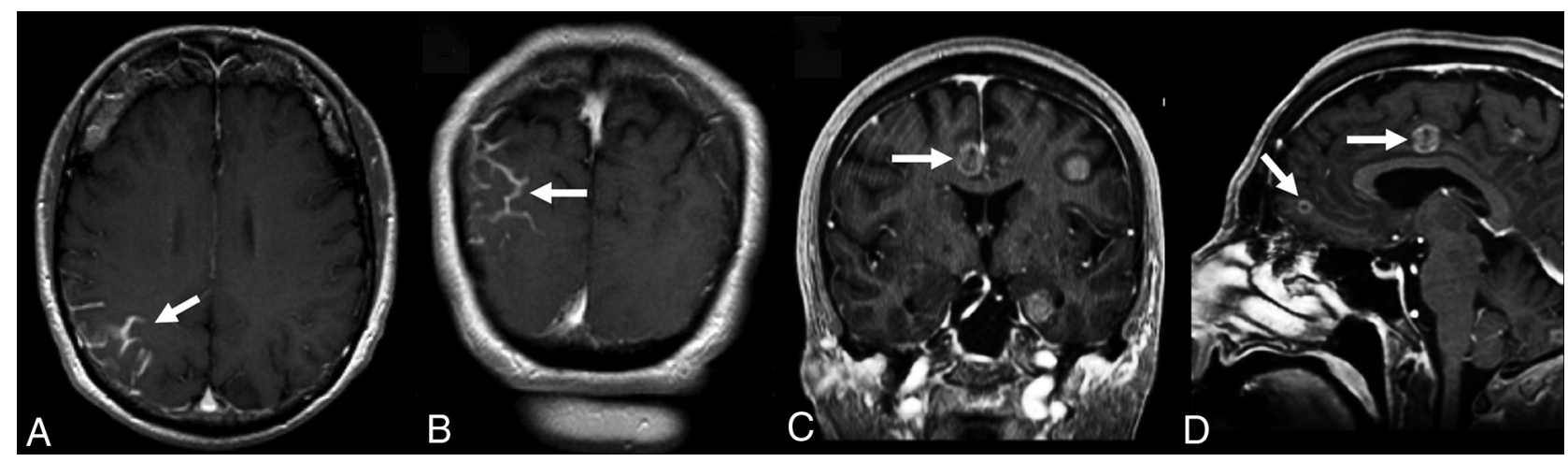

FIG 6. Examples of nonmeasurable disease in a patient with NSCLC brain metastases. $A$ and $B$, Leptomeningeal metastatic disease in the right parietal lobe (white arrows). $C$ and $D, A$ different patient with small-cell lung cancer demonstrates completely cystic metastases (white arrows) that do not have a measurable solidly enhancing component. Both leptomeningeal disease and completely cystic metastases are considered nonmeasurable disease by the RANO criteria.

Up to 5 measurable lesions should be identified as target lesions. If the patient has $>5$ measurable lesions, then the target lesions should be selected while giving preference to the following factors:

- Largest size.

- Increasing size on consecutive imaging studies.

- No prior local treatment, including an operation, SRS, and so forth.

After the target lesions are selected, the longest diameter (including only the enhancing nodular component of the lesion) should be recorded for each of the target lesions (Fig 5). The sum of the longest diameter of all target lesions should also be included in the report. If there are no lesions that meet the criteria for a measurable target lesion, then the patient is said to have nonmeasurable disease. The RANO group suggests that studies that include the assessment of the CNS response to therapy as their primary end point should not include patients with nonmeasurable disease. ${ }^{63}$

Additional factors including a description of morphologic features at initial imaging and the location of brain metastases may prove important in the era of precision medicine and targeted therapies, including TKIs. One study of 144 patients with EGFRmutated NSCLC brain metastases treated with a first- or secondgeneration EGFR-TKI found that erlotinib achieved a longer PFS than gefitinib or afatinib only in patients who demonstrated poor prognostic factors on MR imaging such as tumor necrosis, rim enhancement, or tumor location in the frontal lobe, putamen, or cerebellum. ${ }^{65}$ In patients without these poor prognostic imaging characteristics, the PFS was comparable among erlotinib, gefitinib, and afatinib. This finding suggests that the initial imaging features of brain metastases may be useful in predicting outcomes in patients treated with novel targeted therapies.

\section{Nontarget Lesions}

Although the nontarget brain metastases do not need to be measured, they should be identified and included in the baseline report. This is important so that on subsequent follow-up imaging these lesions can also be assessed for progression and new lesions can be easily identified.

\section{Evaluation of Lesions on Follow-Up Imaging}

On follow-up imaging, the previously identified target lesions should be found and the largest diameter of each lesion as well of as the sum of these unidirectional measurements should be recorded. Next, the nontarget lesions should be compared with measurements on prior studies and results of the evaluation of whether these lesions are increased, decreased, or unchanged in size should be recorded. Even if the target lesions are unchanged or decreased in size, if there is unequivocal and substantial progression of the nontarget lesions, the patient is still considered to have progressive disease. Finally, evaluation for any new brain metastasis should be performed. A clear statement of whether any new lesion is larger than $5 \mathrm{~mm}$ in diameter; visible in axial, sagittal, and coronal planes; and definitively not due to artifacts should be given in the report. In the case of questionable new lesions, the patient and oncologist may choose to continue therapy and obtain short-term follow-up imaging to re-evaluate the lesion in question.

\section{Response to Therapy}

The RANO criteria for response to therapy in brain metastases take several clinical factors into account, including changes in the corticosteroid dose and Karnofsky Performance Scale. Any significant increase in the corticosteroid dose or worsening in performance status that cannot be returned to baseline is consistent with progressive disease. ${ }^{63}$ Thus, unless the radiologist has access to both of these factors in the clinical history, it would be sensible to not include the definitive RANO criteria response in a report before discussing the patient with the referring oncology team. However, follow-up imaging is one of the major criteria for determining response to therapy according to the RANO criteria. From an imaging standpoint, the following are the criteria for each possible response to therapy: ${ }^{63}$

- Complete response: complete resolution of all target and nontarget metastases with no new enhancing lesions.

- Partial response: decrease of at least $30 \%$ in the sum of the longest diameter of the target lesions compared with baseline, no change or decrease in the nontarget lesions, and no new lesions. 
- Progressive disease: either an increase of at least $20 \%$ in the sum of the longest diameter of the target lesions from the nadir, unequivocal progression of nontarget lesions, or any new lesion.

- Stable disease: change in the sum of the longest diameter of the target lesions between $30 \%$ decrease and $20 \%$ increase, stable or improved nontarget lesions, and no new lesions.

Finally, the RANO group suggests that when reporting the response to therapy in patients with brain metastases, the CNS disease should be separated from the non-CNS disease. For nonCNS disease, the criteria established in RECIST 1.1 are recommended. ${ }^{62}$ This approach gives the flexibility for a trial to calculate both local CNS progression-free survival, non-CNS progression-free survival, and bicompartmental progressionfree survival. Any of these outcomes could then be used as a primary end point for the trial. This flexibility is potentially beneficial in situations in which patients have local CNS progression and a favorable response in the non-CNS compartment for undergoing concurrent local CNS therapy and being able to stay in the trial.

When patients with NSCLC with brain metastases are on immunotherapy or have received local therapy with WBRT or SRS, new lesions alone may not constitute progression of disease and instead may be due to pseudoprogression. ${ }^{63}$ Pseudoprogression refers to a transient increase in tumor size on imaging shortly after treatment due to edema, necrosis, or immune cell infiltration. This initial radiographic growth can mimic true progression, but unlike true progression, it is subsequently followed by a reduction in tumor burden. Pseudoprogression after radiation therapy, especially SRS, is a well-recognized phenomenon in patients with brain metastases and has been shown to occur in up to $25 \%-30 \%$ of patients radiographically after SRS. ${ }^{66,67}$ Studies have also shown that it may occur in a higher rate in NSCLC-associated brain metastases and that $A L K$ mutation may be an added risk factor. $^{68}$ Whether TKI therapy after SRS and/or WBRT is an added risk remains to be determined, and there is conflicting evidence on the topic. Before the use of second-generation $A L K$ inhibitors, there were no reports of radiation necrosis during crizotinib use, including when it was used after patients had undergone SRS. ${ }^{48,69}$ There have been reports of radiation necrosis in patients on alectinib for $A L K$-mutated NSCLC months to years after radiation therapy. ${ }^{48,70}$ The RANO criteria do give some guidance in these situations; and often short-term follow-up, advanced MR imaging or PET, or biopsy must be performed to find a more definitive answer. ${ }^{63}$ Because TKIs are the focus of this article and they have not been established as a risk factor for pseudoprogression, an indepth discussion of the guidelines pertaining to pseudoprogression will not be included. It is, however, important to keep in mind the possibility of pseudoprogression in these patients in the correct clinical and imaging scenario.

Studies evaluating the best imaging parameters to evaluate the response to TKI therapy have not yet been performed; however, many believe that the unidirectional method proposed by the RANO group may not be the best approach. Some have suggested that volumetric measurements are a more accurate measurement of changes in the number of cancer cells and better account for irregular shapes and cystic changes that frequently occur in brain metastases after treatment. A study on the treatment of melanoma brain metastases with SRS demonstrated that volumetric measurements were a better predictor of overall survival and the need for salvage WBRT compared with linear measurements. ${ }^{71}$ The RANO group does admit that volumetric measurements may prove to be a better method; however, they believe that there are too little data, availability, and standardization of volumetric measurements to recommend this over unidirectional measurements at this time. Furthermore, until volumetric measurements become more automated, they require higher cost and more effort to provide these measurements.

Unlike metastases treated with systemic cytotoxic chemotherapy, which typically demonstrate response to therapy as a shrinkage in size and decreased surrounding edema, metastases treated with SRS and WBRT often undergo more complex morphologic changes after treatment. ${ }^{72}$ Kang et al $^{72}$ described early-stage changes, including central and perilesional edema with an occasional transient increase in the size of the enhancing brain metastasis days after SRS. These changes are followed by central cavitation and necrosis, often with indistinct enhancing borders. ${ }^{72}$ Finally, in the chronic stage, the lesion remains as a peripherally enhancing glial scar without surrounding edema. ${ }^{72}$ Because of these dynamic changes in size with difficult-tomeasure centrally necrotic lesions, SRS has been the subject of study for many other imaging biomarkers to predict a response to therapy, including MR diffusion, MR perfusion (especially dynamic contrast enhancement), and PET studies using 3-deoxy-3-[ $\left[{ }^{18} \mathrm{~F}\right]$ fluorothymidine or $2-\left[{ }^{18} \mathrm{~F}\right]$ fluoro-2deoxy-d-glucose. ${ }^{73-77}$ One study concluded that the response to SRS treatment of brain metastases could be predicted as soon as 7-10 days after treatment using MR diffusion-weighted imaging. ${ }^{76}$ However, after many studies in search of the best biomarkers, factors as simple as whether an increase or decrease in diffusivity predicts a good response to SRS still remain controversial and are likely related to the timing of the follow-up studies. ${ }^{73,76,77}$ Because of the complexity of the physiologic changes happening at the cellular level in brain metastases after different types of treatment, accepting new, advanced MR imaging or PET biomarkers as a means to assess treatment response should not be haphazard. Furthermore, the use of different imaging biomarkers for different types of therapy may the best means of evaluation. Well-designed prospective studies on imaging biomarkers are needed to fully understand the best biomarkers for assessment of the response to TKIs and other methods of treatment.

In our experience, morphologic changes after TKIs more closely follow the systemic cytotoxic chemotherapy pattern of response including decreased size and surrounding edema of mostly solidly enhancing lesions. However, further studies need to systematically evaluate the pattern of morphologic changes in brain metastases after treatment with TKIs, especially because bizarre imaging appearances, including nearly entirely cystic brain metastases, have been described in patients undergoing treatment with TKIs. Also, if size criteria prove to be the best means of measuring response to therapy, unidirectional, bidirectional, and volumetric measurements should be compared to see which method best predicts early response or progression and longterm patient outcomes. 


\section{CONCLUSIONS}

In recent years, several systemic therapies have been developed that demonstrate efficacy in NSCLC metastatic to the brain. It is essential for radiologists to be informed about these novel therapeutic agents to evaluate the intracranial response to therapy on imaging in patients undergoing treatment with these drugs. As the systemic chemotherapeutic options for metastatic NSCLC evolve, the assessment of the responses of brain metastases on imaging is becoming ever more critical for evaluating and managing patients with metastatic NSCLC.

\section{REFERENCES}

1. Baik CS, Chamberlain MC, Chow LQ. Targeted therapy for brain metastases in EGFR-mutated and ALK-rearranged non-small-cell lung cancer. $J$ Thorac Oncol 2015;10:1268-78 CrossRef Medline

2. Hall WA, Djalilian HR, Nussbaum ES, et al. Long-term survival with metastatic cancer to the brain. Med Oncol 2000;17:279-86 CrossRef Medline

3. Proto C, Imbimbo M, Gallucci R, et al. Epidermal growth factor receptor tyrosine kinase inhibitors for the treatment of central nervous system metastases from non-small cell lung cancer: the present and the future. Transl Lung Cancer Res 2016;5:563-78 CrossRef Medline

4. Mehta MP, Rodrigus $\mathrm{P}$, Terhaard CHJ, et al. Survival and neurologic outcomes in a randomized trial of motexafin gadolinium and whole-brain radiation therapy in brain metastases. $J$ Clin Oncol 2003;21:2529-36 CrossRef Medline

5. Franciosi V, Cocconi G, Michiara M, et al. Front-line chemotherapy with cisplatin and etoposide for patients with brain metastases from breast carcinoma, nonsmall cell lung carcinoma, or malignant melanoma: a prospective study. Cancer 1999;85:1599-1605 Medline

6. Petrelli F, Ghidini M, Lonati V, et al. The efficacy of lapatinib and capecitabine in HER-2 positive breast cancer with brain metastases: a systematic review and pooled analysis. Eur J Cancer 2017;84:141-48 CrossRef Medline

7. Verma J, Jonasch E, Allen P, et al. Impact of tyrosine kinase inhibitors on the incidence of brain metastasis in metastatic renal cell carcinoma. Cancer 2011;117:4958-65 CrossRef Medline

8. Kerr KM, López-Ríos F. Precision medicine in NSCLC and pathology: how does ALK fit in the pathway? Ann. Oncol 2016;27:ii16-24 CrossRef Medline

9. Lindeman NI, Cagle PT, Aisner DL, et al. Updated molecular testing guideline for the selection of lung cancer patients for treatment with targeted tyrosine kinase inhibitors. Arch Pathol Lab Med 2018;142:321-46 CrossRef Medline

10. Narita Y, Matsushima Y, Shiroiwa T, et al. Cost-effectiveness analysis of EGFR mutation testing and gefitinib as first-line therapy for non-small cell lung cancer. Lung Cancer 2015;90:71-77 CrossRef Medline

11. Holleman MS, Al MJ, Zaim R, et al. Cost-effectiveness analysis of the first-line EGFR-TKIs in patients with non-small cell lung cancer harbouring EGFR mutations. Eur J Health Econ 2019 Sep 20. [Epub ahead of print] CrossRef Medline

12. Djalalov S, Beca J, Hoch JS, et al. Cost effectiveness of EML4-ALK fusion testing and first-line crizotinib treatment for patients with advanced ALK-positive non-small-cell lung cancer. J Clin Oncol 2014;32:1012-19 CrossRef Medline

13. Carlson JJ, Kangho S, Orfanos P, et al. Cost effectiveness of alectinib vs. crizotinib in first-line anaplastic lymphoma kinase-positive advanced non-small-cell lung cancer. Pharmacoeconomics 2018;36:495-504 CrossRef Medline
14. Glitza Oliva IC, Schvartsman G, Tawbi H. Advances in the systemic treatment of melanoma brain metastases. Ann Oncol 2018;29:150920 CrossRef Medline

15. Svokos KA, Salhia B, Toms SA. Molecular biology of brain metastasis. Int J Mol Sci 2014;15:9519-30 CrossRef Medline

16. Löscher W, Potschka H. Blood-brain barrier active efflux transporters: ATP-binding cassette gene family. NeuroRx 2005;2:86-98 CrossRef Medline

17. Connell JJ, Chatain G, Cornelissen B, et al. Selective permeabilization of the blood-brain barrier at sites of metastasis. J Natl Cancer Inst 2013;105:1634-43 CrossRef Medline

18. Tan J, Li M, Zhong W, et al. Tyrosine kinase inhibitors show different anti-brain metastases efficacy in NSCLC: a direct comparative analysis of icotinib, gefitinib, and erlotinib in a nude mouse model. Oncotarget 2017;8:98771-81 CrossRef Medline

19. García-Román J, Zentella-Dehesa A. Vascular permeability changes involved in tumor metastasis. Cancer Lett 2013;335:259-69 CrossRef Medline

20. Wang BX, Ou W, Mao XY, et al. Impacts of EGFR mutation and EGFR-TKIs on incidence of brain metastases in advanced nonsquamous NSCLC. Clin Neurol Neurosurg 2017;160:96-100 CrossRef Medline

21. O'Kane GM, Leighl NB. Systemic therapy of lung cancer CNS metastases using molecularly targeted agents and immune checkpoint inhibitors. CNS Drugs 2018;32:527-42 CrossRef Medline

22. Abdallah SM, Wong A. Brain metastases in non-small-cell lung cancer: are tyrosine kinase inhibitors and checkpoint inhibitors now viable options? Curr Oncol 2018;25:S103-14 CrossRef Medline

23. Park SJ, Kim HT, Lee DH, et al. Efficacy of epidermal growth factor receptor tyrosine kinase inhibitors for brain metastasis in nonsmall cell lung cancer patients harboring either exon 19 or 21 mutation. Lung Cancer 2012;77:556-60 CrossRef Medline

24. Maemondo M, Inoue A, Kobayashi K, et al; North-East Japan Study Group. Gefitinib or chemotherapy for non-small-cell lung cancer with mutated EGFR. N Engl J Med 2010;362:2380-88 CrossRef Medline

25. Pao W, Balak MN, Riely GJ, et al. Molecular analysis of NSCLC patients with acquired resistance to gefitinib or erlotinib. J Clin Oncol 2006;24:7078 CrossRef

26. Hoffknecht P, Tufman A, Wehler T, et al; Afatinib Compassionate Use Consortium (ACUC). Efficacy of the irreversible ErbB family blocker afatinib in epidermal growth factor receptor (EGFR) tyrosine kinase inhibitor (TKI)-pretreated non-small-cell lung cancer patients with brain metastases or leptomeningeal disease. J Thorac Oncol 2015;10:156-63 CrossRef Medline

27. Yu HA, Arcila ME, Rekhtman N, et al. Analysis of tumor specimens at the time of acquired resistance to EGFR TKI therapy in 155 patients with EGFR mutant lung cancers. Clin Cancer Res 2013;19:2240-47 CrossRef Medline

28. Griffin R, Ramirez RA. Molecular targets in non-small cell lung cancer. Ochsner J 2017;17:388-92 Medline

29. Malapelle U, Ricciuti B, Baglivo S, et al. Osimertinib. Recent Results Cancer Res 2018;211:257-76 CrossRef Medline

30. Tan CS, Kumarakulasinghe NB, Huang YQ, et al. Third generation EGFR TKIs: current data and future directions. Mol Cancer 2018;17:1-14 CrossRef Medline

31. Reungwetwattana $T$, Nakagawa $\mathrm{K}$, Cho $\mathrm{BC}$, et al. CNS response to osimertinib versus standard epidermal growth factor receptor tyrosine kinase inhibitors in patients with untreated EGFR-mutated advanced non-small-cell lung cancer. J Clini Oncol 2018 Aug 28. [Epub ahead of print] CrossRef Medline

32. Soria JC, Ohe Y, Vansteenkiste J, et al; FLAURA Investigators. Osimertinib in untreated EGFR-mutated advanced non-small-cell lung cancer. N Engl J Med 2018;378:113-25 CrossRef Medline

33. Costa DB, Shaw AT, Ou SH, et al. Clinical experience with crizotinib in patients with advanced ALK-rearranged non-small-cell lung cancer and brain metastases. J Clin Oncol 2015;33:1881-88 CrossRef Medline 
34. Ricciuti B, De Giglio A, Mecca C, et al. Precision medicine against ALK-positive non-small cell lung cancer: beyond crizotinib. Med Oncol 2018;35:1-18 CrossRef Medline

35. Gadgeel S, Peters $\mathrm{S}$, Mok T, et al. Alectinib versus crizotinib in treatment-naive anaplastic lymphoma kinase-positive (ALK+) nonsmall-cell lung cancer: CNS efficacy results from the ALEX study. Ann Oncol 2018;29:2214-22 CrossRef Medline

36. Peters S, Camidge DR, Shaw AT, et al; ALEX Trial Investigators. Alectinib versus crizotinib in untreated ALK-positive non-smallcell lung cancer. N Engl J Med 2017;377:829-38 CrossRef Medline

37. Crinò L, Ahn MJ, De Marinis F, et al. Multicenter phase II study of whole-body and intracranial activity with ceritinib in patients with ALK-rearranged non-small-cell lung cancer previously treated with chemotherapy and crizotinib: results from ASCEND-2. J Clin Oncol 2016;34:2866-73 CrossRef Medline

38. Camidge DR, Kim HR, Ahn MJ, et al. Brigatinib versus crizotinib in ALK-positive non-small-cell lung cancer. $N$ Engl J Med 2018;379:2027-39 CrossRef Medline

39. Shaw AT, Felip E, Bauer TM, et al. Lorlatinib in ALK- or ROS1rearranged non-small cell lung cancer: an international, multicenter, open-label phase 1 trial. Lancet Oncol 2017;18:1590-99 CrossRef Medline

40. Ou SHI, Zhu VW. CNS metastasis in ROS1+ NSCLC: an urgent call to action, to understand, and to overcome. Lung Cancer 2019;130:201-07 CrossRef Medline

41. Wu YL, Yang JC, Kim DW, et al. Phase II study of crizotinib in East Asian patients with ROS1-positive advanced non-small-cell lung cancer. J Clin Oncol 2018;36:1405-12 CrossRef Medline

42. Ahn M, Cho BC, Siena S, et al. OA 14.06 entrectinib in patients with locally advanced or metastatic ROS1 fusion-positive nonsmall cell lung cancer (NSCLC). J Thorac Oncol 2017;12:S178 CrossRef

43. Ou S, Shaw A, Riely G, et al. OA02.03 clinical activity of lorlatinib in patients with ROS1+ advanced non-small cell lung cancer: phase 2 study cohort EXP-6. J Thorac Oncol 2018;13:S322-23 CrossRef

44. Lim SM, Kim HR, Lee JS, et al. Open-label, multicenter, phase II study of ceritinib in patients with non-small-cell lung cancer harboring ROS1 rearrangement. J Clin Oncol 2017;35:2613-18 CrossRef Medline

45. Ding PN, Lord SJ, Gebski V, et al. Risk of treatment-related toxicities from EGFR tyrosine kinase inhibitors: a meta-analysis of clinical trials of gefitinib, erlotinib, and afatinib in advanced EGFRmutated non-small cell lung cancer. J Thorac Oncol 2017;12:633-43 CrossRef Medline

46. Hou H, Sun D, Liu K, et al. The safety and serious adverse events of approved ALK inhibitors in malignancies: a meta-analysis. Cancer Manag Res 2019;11:4109-18 CrossRef Medline

47. Del Valle MF, Chang AY. Real world experience on treatment, outcome and toxicity of crizotinib in patients with anaplastic lymphoma kinase positive advanced non-small cell lung cancer. $J$ Thorac Dis 2019;11:3864-73 CrossRef Medline

48. Ou SH, Klempner SJ, Azada MC, et al. Radiation necrosis presenting as pseudoprogression (PsP) during alectinib treatment of previously radiated brain metastases in ALK-positive NSCLC: implications for disease assessment and management. Lung Cancer 2015;88:355-59 CrossRef Medline

49. Song YP, Colaco RJ. Radiation necrosis: a growing problem in a case of brain metastases following whole brain radiotherapy and stereotactic radiosurgery. Cureus 2018;10:e2037 CrossRef Medline

50. Shah RR. Anti-angiogenic tyrosine kinase inhibitors and reversible posterior leukoencephalopathy syndrome: could hypomagnesaemia be the trigger? Drug Saf 2017;40:373-86 CrossRef Medline

51. Shankar J, Banfield J. Posterior reversible encephalopathy syndrome: a review. Can Assoc Radiol J 2017;68:147-53 CrossRef Medline

52. Yamamoto M, Serizawa T, Shuto T, et al. Stereotactic radiosurgery for patients with multiple brain metastases (JLGK0901): a multi- institutional prospective observational study. Lancet Oncol 2014;15:387-95 CrossRef Medline

53. Yamamoto M, Serizawa T, Higuchi $Y$, et al. A multi-institutional prospective observational study of stereotactic radiosurgery for patients with multiple brain metastases (JLGK0901 study update): irradiation-related complications and long-term maintenance of Mini-Mental State Examination scores. Int J Radiat Oncol Biol Phys 2017;99:31-40 CrossRef Medline

54. Berghoff A, Preusser M. New developments in brain metastases. Ther Adv Neurol Disord 2018;11:1756286418785502 CrossRef Medline

55. Jindal V, Gupta S. Expected paradigm shift in brain metastases therapy: immune checkpoint inhibitors. Mol Neurobiol 2018;55:707278 CrossRef Medline

56. Kelly WJ, Shah NJ, Subramaniam DS. Management of brain metastases in epidermal growth factor receptor mutant non-small-cell lung cancer. Front Oncol 2018;8:208-09 CrossRef Medline

57. Shepard MJ, Xu Z, Donahue J, et al. Stereotactic radiosurgery with and without checkpoint inhibition for patients with metastatic non-small cell lung cancer to the brain: a matched cohort study. $J$ Neurosurg 2019 Jul 26. [Epub ahead of print] CrossRef Medline

58. Chen L, Douglass J, Kleinberg L, et al. Concurrent immune checkpoint inhibitors and stereotactic radiosurgery for brain metastases in non-small cell lung cancer, melanoma, and renal cell carcinoma. Int J Radiat Oncol Biol Phys 2018;100:916-25 CrossRef Medline

59. Narayanan V, Honce MJ, Mehrotra S, et al. Cystic brain metastases occurring in anaplastic lymphoma kinase gene rearranged nonsmall-cell lung cancer patients receiving crizotinib. Clin Lung Cancer 2016;17:85-90 CrossRef Medline

60. Essenmacher AC, Watal P, Bathla G, et al. Brain metastases from adenocarcinoma of the lung with truly cystic magnetic resonance imaging appearance. Clin Imaging 2018;52:203-07 CrossRef Medline

61. Zee YK, Chin TM, Wong ASC. Fatal cystic change of brain metastasis after response to gefitinib in non-small-cell lung cancer. J Clin Oncol 2009;27:145-46 CrossRef Medline

62. Schwartz LH, Litière S, de Vries E, et al. RECIST 1.1: update and clarification-from the RECIST Committee. Eur J Cancer 2016;62:132-37 CrossRef Medline

63. Lin NU, Lee EQ, Aoyama H, et al; Response Assessment in NeuroOncology (RANO) group. Response assessment criteria for brain metastases: proposal from the RANO group. Lancet Oncol 2015;16: e270-78 CrossRef Medline

64. Chamberlain M, Junck L, Brandsma D, et al. Leptomeningeal metastases: a RANO proposal for response criteria. Neuro Oncol 2017;19:484-92 CrossRef Medline

65. Lin CY, Chang CC, Su PL, et al. Brain MRI imaging characteristics predict treatment response and outcome in patients with de novo brain metastasis of EGFR-mutated NSCLC. Medicine (Baltimore) 2019;98:e16766 CrossRef Medline

66. Minniti G, Clarke E, Lanzetta G, et al. Stereotactic radiosurgery for brain metastases: analysis of outcome and risk of brain radionecrosis. Radiat Oncol 2011;6:48 CrossRef Medline

67. Kohutek ZA, Yamada Y, Chan TA, et al. Long-term risk of radionecrosis and imaging changes after stereotactic radiosurgery for brain metastases. J Neurooncol 2015;125:149-56 CrossRef Medline

68. Miller JA, Bennett EE, Xiao R, et al. Association between radiation necrosis and tumor biology after stereotactic radiosurgery for brain metastasis. Int J Radiat Oncol Biol Phys 2016;96:1060-69 CrossRef Medline

69. Gan GN, Weickhardt AJ, Scheier B, et al. Stereotactic radiation therapy can safely and durably control sites of extra-central nervous system oligoprogressive disease in anaplastic lymphoma kinasepositive lung cancer patients receiving crizotinib. Int $J$ Radiat Oncol Biol Phys 2014;88:892-98 CrossRef Medline

70. Ou SH, Weitz M, Jalas JR, et al. Alectinib induced CNS radiation necrosis in an ALK + NSCLC patient with a remote ( 7 years) history of brain radiation. Lung Cancer 2016;96:15-18 CrossRef Medline 
71. LeCompte MC, McTyre E, Henson A, et al. Survival and failure outcomes predicted by brain metastasis volumetric kinetics in melanoma patients following upfront treatment with stereotactic radiosurgery alone. Cureus 2017;9:e1934 CrossRef Medline

72. Kang TW, Kim ST, Byun HS, et al. Morphological and functional MRI, MRS, perfusion and diffusion changes after radiosurgery of brain metastasis. Eur J Radiol 2009;72:370-80 CrossRef Medline

73. Jakubovic R, Zhou S, Heyn C, et al. The predictive capacity of apparent diffusion coefficient (ADC) in response assessment of brain metastases following radiation. Clin Exp Metastasis 2016;33:277-84 CrossRef Medline

74. Abdulla DS, Scheffler M, Brandes V, et al. Monitoring treatment response to erlotinib in EGFR-mutated non-small-cell lung cancer brain metastases using serial O-(2- [18 F]fluoroethyl)-L-tyrosine PET. Clin Lung Cancer 2019;20:e148-51 CrossRef Medline

75. Essig M, Waschkies M, Wenz F, et al. Assessment of brain metastases with dynamic susceptibility-weighted contrast-enhanced MR imaging: initial results. Radiology 2003;228:193-99 CrossRef Medline

76. Mahmood F, Johannesen HH, Geertsen P, et al. Repeated diffusion MRI reveals earliest time point for stratification of radiotherapy response in brain metastases. Phys Med Biol 2017;62:2990-3002 CrossRef Medline

77. Huang CF, Chou $\mathrm{HH}, \mathrm{Tu} \mathrm{HT}$, et al. Diffusion magnetic resonance imaging as an evaluation of the response of brain metastases treated by stereotactic radiosurgery. Surg Neurol 2008;69:62-68 CrossRef Medline 